\title{
Article \\ Reliability and Reproducibility of Landmark Identification in Unilateral Cleft Lip and Palate Patients: Digital Lateral Vis-A-Vis CBCT-Derived 3D Cephalograms
}

\author{
Anuraj Singh Kochhar ${ }^{1, *(\mathbb{D})}$, Ludovica Nucci ${ }^{2}$, Maninder Singh Sidhu ${ }^{3}$, Mona Prabhakar $\left.{ }^{3}{ }^{(}\right)$, Vincenzo Grassia ${ }^{2}{ }^{\circ}$, \\ Letizia Perillo ${ }^{2}$, Gulsheen Kaur Kochhar ${ }^{4}$, Ritasha Bhasin ${ }^{5}$, Himanshu Dadlani ${ }^{6}\left(\mathbb{D}\right.$ and Fabrizia d'Apuzzo ${ }^{2}(\mathbb{D})$ \\ 1 Former Consultant Orthodontist Max Hospital Gurgaon, Haryana 122001, India \\ 2 Multidisciplinary Department of Medical-Surgical and Dental Specialties, \\ University of Campania Luigi Vanvitelli, 80138 Naples, Italy; ludovica.nucci@unicampania.it (L.N.); \\ grassiavincenzo@libero.it (V.G.); letizia.perillo@unicampania.it (L.P.); fabrizia.dapuzzo@unicampania.it (F.d.) \\ 3 Department of Orthodontics \& Dean, Research \& Development Faculty of Dental Sciences, \\ SGT University Gurugram, Haryana 122505, India; deanresearch@sgtuniversity.org (M.S.S.); \\ mona.prabhakar@sgtuniversity.org (M.P.) \\ 4 Department of Pediatric \& Preventive Dentistry, National Dental College \& Hospital, Punjab 140507, India; \\ gulsheenuppal@gmail.com \\ 5 Faculty of Dentistry, University of Toronto, Toronto, ON M5G1G6, Canada; ritasha.bhasin@mail.utoronto.ca \\ 6 Senior Consultant Department of Dentistry (Periodontology), Max Hospital, Gurgaon, Haryana 122001, India; \\ himdent@hotmail.com \\ * Correspondence: anuraj_kochhar@yahoo.co.in
}

Citation: Kochhar, A.S.; Nucci, L.; Sidhu, M.S.; Prabhakar, M.; Grassia, V.; Perillo, L.; Kochhar, G.K.; Bhasin, R.; Dadlani, H.; d'Apuzzo, F. Reliability and Reproducibility of Landmark Identification in Unilateral Cleft Lip and Palate Patients: Digital Lateral Vis-A-Vis CBCT-Derived 3D Cephalograms. J. Clin. Med. 2021, 10, 535. https://doi.org/10.3390/ jcm10030535

Academic Editors: Emmanuel Andrès and Gianrico Spagnuolo

Received: 3 January 2021

Accepted: 26 January 2021

Published: 2 February 202

Publisher's Note: MDPI stays neutral with regard to jurisdictional claims in published maps and institutional affiliations.

Copyright: (c) 2021 by the authors Licensee MDPI, Basel, Switzerland. This article is an open access article distributed under the terms and conditions of the Creative Commons Attribution (CC BY) license (https:// creativecommons.org/licenses/by/ $4.0 /)$.
Abstract: Background: The aim of the retrospective observational study was to compare the precision of landmark identification and its reproducibility using cone beam computed tomography-derived 3D cephalograms and digital lateral cephalograms in unilateral cleft lip and palate patients. Methods: Cephalograms of thirty-one (31) North Indian children (18 boys and 13 girls) with a unilateral cleft lip and palate, who were recommended for orthodontic treatment, were selected. After a thorough analysis of peer-reviewed articles, 20 difficult-to-trace landmarks were selected, and their reliability and reproducibility were studied. These were subjected to landmark identification to evaluate interobserver variability; the coordinates for each point were traced separately by three different orthodontists $\left(\mathrm{OB}_{\mathrm{A}}, \mathrm{OB}_{\mathrm{B}}, \mathrm{OB}_{\mathrm{C}}\right)$. Statistical analysis was performed using descriptive and inferential statistics with paired $t$-tests to compare the differences measured by the two methods. Real-scale data are presented in mean \pm SD. A $p$-value less than 0.05 was considered as significant at a $95 \%$ confidence level. Results: When comparing, the plotting of points posterior nasal spine (PNS) $(p<0.05)$, anterior nasal spine (ANS) $(p<0.01)$, upper 1 root tip $(p<0.05)$, lower 1 root tip $(p<0.05)$, malare $(p<0.05)$, pyriforme $(p<0.05)$, porion $(p<0.01)$, and basion $(p<0.05)$ was statistically significant. Conclusion: In patients with a cleft lip and palate, the interobserver identification of cephalometric landmarks was significantly more precise and reproducible with cone beam computed tomography -derived cephalograms vis-a-vis digital lateral cephalograms.

Keywords: cleft; accuracy; unilateral cleft lip and palate; CBCT; interobserver; cephalogram

\section{Introduction}

Since its advent in 1931 [1], conventional cephalometry has been one of the essential diagnostic tools for analyzing orthodontic problems, maxillofacial deformities, evaluating growth, and planning treatment [2]. However, difficulty in locating imperceivable anatomic landmarks and superimposition of craniofacial structures, owing to the two-dimensional (2D) representation of three-dimensional (3D) anatomy, are amongst the limitations of traditional cephalometrics [3-5]. Young cleft lip and palate (CLP) patients usually present with a flattened cranial base, midface deficiency with a retruded maxilla and elongated mandible, 
anterior and/or posterior crossbites, and an increased vertical dimension, thereby making the recognition of cephalometric landmarks even more arduous [4,5].

The localization of landmarks like point A, the anterior nasal spine (ANS), and the posterior nasal spine (PNS) is challenging due to the decreased opacity resulting from the cleft [6]. The remodeling of the tooth germs in young patients, especially in the anterior contour of the maxilla, can be a possible cause for the same according to Hotz and Gnoinski [7]. According to published data, it is difficult to interpret radiographs in patients with CLP before the exfoliation of the incisors for the abovementioned problems, thus questioning the reliability of cephalometric measurements for the same $[8,9]$.

In the present times, when imaging has been revolutionized, cone beam computed tomography (CBCT) aids in avoiding the anatomic superimpositions and problems caused by magnification, thereby permitting the evaluation of the craniofacial structures from unobstructed perspectives with minimal distortion. Three-dimensional (3D) images from CBCT scans can be rotated easily by changing the rotational axis, as convenient to the observer [2,10]. Specifically, regarding cleft patients, previous studies have advocated CBCT as an exceptional tool for the determination of bone volume [11-14], bone and root morphology, the assessment of tooth development in the vicinity of the cleft area [15-18], and soft tissue depth.

In orthodontics, cephalograms are repeatedly traced and reviewed. For impeccable treatment planning, the reliability and reproducibility of these anatomical landmarks are imperative, especially in patients with CLP where the identification of landmarks is highly challenging and, therefore, difficult to perceive and reproduce. Although the synchronal literature in the past several years has emphasized the pivotal role of CBCT to determine the reliability [19-27] of anatomic landmarks, there is a paucity of studies for the same, along with their reproducibility in CLP patients versus cephalometrics where the localization of anatomy is challenging.

A lot of studies have emphasized the difficulty in the plotting of bilateral landmarks [2,19-21], but none have been done in a compromised craniofacial morphology. To know the actual degree of midfacial retrusion along with the compromised craniofacial morphology that is usually present in cleft patients, the accuracy of landmark identification plays an important role $[6,26]$.

Therefore, the present study was conducted to compare the reliability and reproducibility of landmark identification using two systems: CBCT-derived 3D cephalograms vis-a-vis digital lateral cephalograms in unilateral cleft lip and palate (UCLP) patients.

\section{Materials and Methods}

\subsection{Ethical Approval}

Approval for the retrospective observational study was obtained from Shree Guru Gobind Singh Tricentenary (SGT) Dental College, Hospital, and Research Institute, Budhera, Gurgaon, India (SGTDC/PPL/Com./E.C./14 August 2010) (institutional ethical committee). All records acquired from the Department of Orthodontics and Dentofacial Orthopedics from March 2011 to May 2013 were used only for research purposes, for which prior informed consent had been taken.

\subsection{Methodology}

Examination of records of 54 North Indian children (aged 10-14 years) with a repaired $\mathrm{CL} \pm \mathrm{P}$ anomaly was done. For the sample size estimation in the present study, power analysis at $80 \%$ power, a 0.5 alpha level, and an effect size of 0.8 suggested that a minimum of 21 patients were required. Records of thirty-one children (Table 1) who had primary CLP repair performed before 18 months of age, with no secondary alveolar bone grafts and no prior orthodontic/orthopedic appliance intervention (but recommended for comprehensive orthodontic treatment), were selected and designated as samples. Patients' records not fulfilling any of the above inclusion criteria or with any syndrome or mental retardation as documented in the medical history were excluded. 
Table 1. Sample Characteristics.

\begin{tabular}{ccccccccccc}
\hline & \multicolumn{3}{c}{ Boys $(\boldsymbol{n = 1 8})$} & \multicolumn{3}{c}{ Girls $(\boldsymbol{n = 1 3})$} & \multicolumn{3}{c}{ Total Sample $(\boldsymbol{n = 3 1 )}$} \\
\hline & Mean & SD & Range & Mean & SD & Range & Mean & SD & Range \\
\hline Age (yrs.) & 12.035 & 0.690 & $10-14$ & 12.13 & 0.724 & $10-14$ & 12.09 & 0.698 & $10-14$ \\
\hline
\end{tabular}

Cephalograms had been acquired using PlanmecaPromax (Planmeca Co, Helsinki, Finland) in a natural head position, stabilized by ear rods. The scans were obtained at $66 \mathrm{kvp}$ and $5 \mathrm{~mA}$. The JPG images were obtained and transferred to the Nemoceph NX software (Visiodent, Saint-Denis, France) for calibration and analysis, which was done with a scale present on the X-ray as a $10 \mathrm{~mm}$ measurement marked on the cephalogram.

CBCT scans had been acquired using an i-CAT next-generation machine (Imaging Sciences International, Hatfield, PA, USA) with a field of view (fov) of $17 \times 22 \mathrm{~cm}$ and a scan time of $26 \mathrm{~s}$. The data gathered were saved in DICOM (version 1.7) format with an isometric voxel size of $0.25 \mathrm{~mm}$. The DICOM images, using InVivoDental 5.0 (Anatomage, anatomy imaging software, San Jose, CA, USA), were reoriented according to Kochhar et al. [25]. According to a recent study, the precision of landmark plotting is negligibly affected by the orientation of CBCT images, but for the current study, reoriented images were utilized [2]. Once the images were reoriented, $3 \mathrm{D}$ reconstruction of the lateral cephalogram was done and saved as a JPG. The digitized and calibrated images from the iCAT CBCT machine were transferred in the Nemoceph software, and the $X$ and $Y$ coordinates were determined.

Various relevant peer-reviewed articles were considered (Table 2), 20 difficult-totrace landmarks were then selected (Table 3), and their reliability and reproducibility were checked.

Table 2. Studies reviewed to determine difficult-to-trace landmarks.

\begin{tabular}{ccc}
\hline S.No. & Author (Year) & Difficult-to-Trace Points in These Studies/Significant Findings \\
\hline 1. & Bongaarts CA et al., 2008 [6] & Point A, ANS, and PNS \\
\hline & & Anterior Posterior (AP): Point A, ANS, Point B, Go, Mandibular Incisor Tip \\
2. & Ludlow JB et al., 2009 [21] & Cephalocaudal (CC): ANS, Co, Go, Na, Or \\
& & Avg AP and CC: Point A, ANS, Co, Go, Mandibular Incisor Tip, Me, Na \\
\hline
\end{tabular}

$$
\text { INTER-OBSERVER RELIABILITY }
$$

$X$ Coordinate: Subspinale, ANS, Ba, Co, L1 Root, sigmoid notch

Y Coordiate: Ba, co, go, L1tip, Or, Po, S, Sigmoid notch, U1 tip

3. Chien PC et al., 2009 [3] INTRA-OBSERVER RELIABILITY

$X$ coordinate: $\mathrm{Ba}$

Y coordinate: Ba, L1 tip, Me, Or, Sella, Sigmoid Notch

\begin{tabular}{|c|c|c|}
\hline 4. & Grauer D et al., 2010 [28] & ANS, U1tip, Point B \\
\hline 5. & Chang ZC et al., 2011 [29] & $\begin{array}{l}\text { Intercept: S, Or, ANS, Point A, L1, L1R, Point B, Me, Go, Ba, PNS } \\
\text { Interaction with CBCT mode: N, Gn, Me, Ba. }\end{array}$ \\
\hline 6. & Zamora N et al., 2012 [30] & Supraorbitale, Right zygion, PNS \\
\hline 7. & Katkar RA et al., 2013 [31] & Go, $\mathrm{Na}, \mathrm{Or}, \mathrm{ANS}$ and $\mathrm{Md} 1$ root. \\
\hline 8. & Durao APR et al., 2015 [32] & $\begin{array}{l}\text { X coordinate: } \text { Or, Po, Go, Co, PNS } \\
\text { Y coordinate: Co, Point B, Point A }\end{array}$ \\
\hline 9. & Neiva MB et al., 2016 [33] & Right Co, Gn, Left ramus point, Right and left zygomatic suture \\
\hline 10. & Ghoneima A et al., 2017 [34] & $\begin{array}{l}\text { X coordinate: Ba, Point B, Me, U1, L1 } \\
\text { Y coordinate: } \mathrm{Ba} \text {, PNS. }\end{array}$ \\
\hline 11 & Park J et al., 2019 [20] & $\begin{array}{c}\text { Skeletal: Bilateral structures showed more errors than midline structures. Go was } \\
\text { least reliable. }\end{array}$ \\
\hline
\end{tabular}

Point A, Point B, Anterior Nasal Spine (ANS), Condylion (Co), Posterior Nasal Spine (PNS), Gonion (Go), Mandibular Incisor Tip (L1), Maxillary incisal tip (U1), Nasion (Na), Oribitale (Or), Menton (Me), Supspinale, Sigmond notch, Porion (Po), Sella (S), Basion (Ba), Gnathion (Gn), Supraorbitale, Zygion, Zygomatic suture. 
Table 3. Twenty difficult-to-trace landmarks.

\begin{tabular}{|c|c|c|}
\hline S.No. & Landmark & Definition of Landmark \\
\hline 1. & Nasion & Intersection of the internasal suture with the nasofrontal suture in the midsagittal plane. \\
\hline 2. & Orbitale & Most inferior point on the infraorbital rim \\
\hline 3. & $\begin{array}{l}\text { Supra } \\
\text { orbitale }\end{array}$ & Most superior point on the infraorbital rim \\
\hline 4. & ANS & Tip of the anterior nasal spine \\
\hline 5. & PNS & Point along the palate immediately inferior to the pterygomaxillary fossa \\
\hline 6. & Point A & Deepest point of the curve of the maxilla, between the anterior nasal spine and the dental alveolus \\
\hline 7. & U1, root tip & Root tip of the maxillary incisor \\
\hline 8. & U1, crown tip & Incisal tip of the maxillary incisor \\
\hline 9. & L1, crown tip & Incisal tip of the mandibular incisor \\
\hline 10. & L1, root tip & Root tip of the mandibular incisor \\
\hline 11. & Malare & Most prominent anterolateral point on the zygomatic bone that lends the malar prominence to the face \\
\hline 12. & Pyriforme & $\begin{array}{c}\text { Anterolateral margin of the nasal aperture represented by the most anteromedial point on the maxilla, } \\
\text { forming the bony alar base }\end{array}$ \\
\hline 13. & Point B & The deepest midline point on the mandible between the infradentale and the pogonion \\
\hline 14. & Pog & Most anterior point on the midsagittal symphysis \\
\hline 15. & Gonion & $\begin{array}{l}\text { Point along the angle of the mandible, midway between the lower border of the mandible posterior } \\
\text { ascending ramus }\end{array}$ \\
\hline 16. & Porion & Most superior point of the right external auditory meatus \\
\hline 17. & Sella & Center of the pituitary fossa of the sphenoid bone \\
\hline 18. & Basion & Most inferior point on the anterior margin of the foramen magnum, at the base of the clivus \\
\hline 19. & MB cusp, U6 & Mesio-buccal cusp of the maxillary first molar \\
\hline 20. & MB cusp, L6 & Mesio-buccal cusp of the mandibular first molar \\
\hline
\end{tabular}

The digitized and calibrated images from Planmeca (a digital cephalometric machine) and iCAT CBCT were transferred to the Nemoceph software, and the $X$ and $Y$ coordinates were determined. The coordinates for each point were traced separately by three different orthodontists (OBA, $\mathrm{OBB}, \mathrm{OBC})$ who were designated as observers to check the variability of the points. Intra-observer differences could be due to the nature of the cephalometric landmark, the image quality, and the blurring of the anatomic structures. In contrast, inter-observer differences might be caused by variations in the observer's training and experience [35].

\subsection{Blinding}

For the prevention of bias, the coordinator created datasets (digital cephalogram and CBCT-generated cephalograms) that were kept in one location and renamed from 1 to 62. All the cephalogram tracings were done two times consecutively by three different observers with a minimum gap of 10 days to eliminate the observer bias in between and to check for the inter-observer variability. Once the tracing was performed, the same coordinator decoded the data into a digital and CBCT-derived cephalogram. These findings were transferred to the excel sheet and subjected to statistical analysis.

\subsection{Statistical Analysis}

The statistical software SPSS version 24.0 was used for the analysis, to compare the findings of the three observers. The centroid for each landmark was obtained by marking 
the coordinates of the mean by all three observers. For the statistical analysis, mean distance (MD), mean deviations from the centroid, and standard deviations were computed. The gold standard observed in the study was the centroid of the markings by the three observers for each landmark. The error in the detection of each landmark was represented by the mean of the distances from the centroid of the observers' markings to each observer's marking. To assess the variation in each axis of all landmarks, the mean deviation was computed. The variations among all the samples of each landmark were represented by standard deviations. To illustrate the distribution of errors over the number of samples, the standard deviations were computed for mean deviation. Statistical analysis was performed by using descriptive and inferential statistics with paired $t$-tests to compare the differences measured by the two methods. Real-scale data are presented in mean \pm SD. A $p$-value less than 0.05 was considered as significant at the $95 \%$ confidence level.

Step 1: The average of the two readings for each observer was calculated separately for the digital and CBCT-derived cephalograms.

$$
\begin{gathered}
\mathrm{OBA}=(\mathrm{Lax}+\mathrm{Lax}) / 2 ; \mathrm{OBB}=(\mathrm{LBx}+\mathrm{LBx}) / 2 ; \mathrm{OBC}=(\mathrm{LCx}+\mathrm{LCx}) / 2: \\
\mathrm{OA}=(\mathrm{Lay}+\mathrm{Lay}) / 2 ; \mathrm{OB}=(\mathrm{LBy}+\mathrm{LBy}) / 2 ; \mathrm{OC}=(\mathrm{LCy}+\mathrm{LCy}) / 2
\end{gathered}
$$

where $\mathrm{x}$ and $\mathrm{y}$ are the coordinates and $\mathrm{A}, \mathrm{B}$, and $\mathrm{C}$ are the observers.

Step 2: The centroid was calculated for both coordinates by using the formula:

$$
\text { Centroid } C L x=((O A x+O B x+O C x) / 3 ; C L y=(O A y+O B y+O C y)) / 3
$$

Step 3: Calculation of the distance for each observer from the centroid for all three observers.

$$
\begin{gathered}
\text { DLA }=\sqrt{ }(C L x A-O x A)^{\wedge} 2+(\text { CLyA }- \text { OyA })^{\wedge} 2, \\
\text { DLB }=\sqrt{ }(C L x B-O x B)^{\wedge} 2+(C L y B-O y B)^{\wedge} 2 \text { and } \\
\text { DLC }=\sqrt{ }(C L x C-O x C)^{\wedge} 2+(C L y C-\text { OyC })^{\wedge} 2
\end{gathered}
$$

Step 4: The mean distance was calculated with

$$
\mathrm{MD}=(\mathrm{DLA}+\mathrm{DLB}+\mathrm{DLC}) / 3
$$

where DL is the distance of the landmark for each observer from the centroid (for observer $\mathrm{A}(\mathrm{OBA}), \mathrm{B}(\mathrm{OBB})$, and $\mathrm{C}(\mathrm{OBC}))$ and $\mathrm{L}$ is any of the 20 landmarks.

Step 5: The mean Distance was calculated for all 20 landmarks in all 20 datasets. This whole process was adopted for each landmark.

\section{Results}

Landmark identification is difficult, especially in patients with a cleft lip and palate. The inter-observer variability of the 20 difficult-to-trace landmarks selected presented an excellent correlation (0.988). The mean distance of the digital and CBCT-derived cephalograms was recorded for all three observers along with the overall mean of the same. A comparison of landmark identification on the digital and CBCT-derived cephalograms was also performed using the $t$-test, and the $p$-value was calculated (a $p$-value less than 0.05 is considered significant at the $95 \%$ confidence level and a $p$-value less than 0.01 is significant at the $99 \%$ confidence level). The inter-observer findings between observers $(\mathrm{OA}, \mathrm{OB}$, and $\mathrm{OC})$ for the digital cephalogram and $\mathrm{CBCT}$-derived cephalograms are presented in Table 4 and Figures 1 and 2. When comparing the digital cephalogram and CBCT-generated cephalograms, the plotting of points PNS $(p<0.05)$, ANS $(p<0.01)$, upper 1 root tip $(p<0.05)$, lower 1 root tip $(p<0.05)$, malare $(p<0.05)$, pyriforme $(p<0.05)$, porion $(p<0.01)$, and basion $(p<0.05)$ was statistically significant. 
Table 4. Comparison of observations obtained by different observers for digital and CBCT derived cephalograms using $t$ test.

\begin{tabular}{|c|c|c|c|c|c|c|c|c|c|c|}
\hline \multirow{3}{*}{ Landmarks } & \multicolumn{10}{|c|}{ Comparisons (Paired $t$-Test) $p$-Value } \\
\hline & \multicolumn{3}{|c|}{ Digital } & \multicolumn{3}{|c|}{ СВСТ } & \multicolumn{4}{|c|}{ Digital vs CBCT } \\
\hline & A VS B & A VS C & B VS C & A VS B & A VS C & B VS C & A & B & $\mathrm{C}$ & OVERALL \\
\hline NASION & 0.362 & 0.520 & 0.093 & 0.112 & 0.713 & 0.060 & 0.366 & 0.732 & 0.460 & 0.841 \\
\hline ORBITALE & 0.191 & 0.417 & 0.861 & 0.119 & 0.133 & 0.773 & 0.972 & 0.481 & 0.184 & 0.910 \\
\hline SUPRAORBITALE & 0.974 & 0.235 & 0.118 & 0.005 & 0.129 & 0.157 & 0.913 & 0.041 & 0.167 & 0.177 \\
\hline PNS & 0.220 & 0.113 & 0.009 & 0.057 & 0.196 & 0.375 & 0.120 & 0.153 & 0.001 & $0.016^{*}$ \\
\hline ANS & 0.115 & 0.111 & $<0.001$ & 0.010 & 0.151 & 0.010 & 0.018 & 0.006 & $<0.001$ & $<0.001$ * \\
\hline POINT A & 0.225 & 0.395 & 0.006 & 0.029 & 0.709 & 0.028 & 0.599 & 0.859 & 0.023 & 0.600 \\
\hline U1 ROOT TIP & 0.028 & 0.678 & 0.037 & 0.033 & 0.238 & 0.109 & 0.095 & 0.119 & 0.038 & $0.039 *$ \\
\hline U1 CROWNTIP & 0.003 & 0.843 & 0.182 & 0.144 & 0.176 & 0.270 & 0.088 & 0.158 & 0.246 & 0.162 \\
\hline L1 CROWNTIP & 0.027 & 0.100 & 0.225 & 0.221 & 0.174 & 0.063 & 0.799 & 0.828 & 0.947 & 0.995 \\
\hline L1 ROOT TIP & 0.052 & 0.761 & 0.099 & 0.031 & 0.246 & 0.025 & 0.067 & 0.353 & 0.017 & $0.013 *$ \\
\hline MALARE & 0.384 & 0.226 & 0.001 & 0.028 & 0.027 & 0.317 & 0.277 & 0.004 & 0.635 & $0.043 *$ \\
\hline PYRIFORME & 0.793 & 0.237 & 0.173 & 0.013 & 0.648 & 0.007 & 0.103 & 0.021 & 0.002 & 0.015 * \\
\hline POINT B & 0.337 & 0.080 & 0.716 & 0.236 & 0.271 & 0.773 & 0.680 & 0.508 & 0.410 & 0.894 \\
\hline POG & 0.003 & 0.568 & 0.014 & 0.097 & 0.496 & 0.164 & 0.074 & 0.678 & 0.040 & 0.069 \\
\hline GONION & 0.323 & 0.337 & 0.120 & 0.061 & 0.643 & 0.039 & 0.127 & 0.143 & 0.149 & 0.136 \\
\hline PORION & 0.352 & 0.041 & 0.028 & 0.318 & 0.455 & 0.962 & $<0.001$ & $<0.001$ & 0.003 & $<0.001$ * \\
\hline SELLA & 0.002 & 0.002 & 0.961 & 0.138 & 0.994 & 0.055 & 0.594 & 0.196 & 0.092 & 0.183 \\
\hline BASION & 0.606 & 0.732 & 0.973 & 0.027 & 0.506 & 0.022 & 0.037 & 0.011 & 0.026 & 0.011 * \\
\hline MB, CUSP U6 & 0.008 & 0.008 & 0.416 & 0.061 & 0.037 & 0.035 & 0.528 & 0.302 & 0.765 & 0.483 \\
\hline MB, CUSP L6 & 0.012 & 0.576 & 0.036 & 0.523 & 0.280 & 0.153 & 0.403 & 0.219 & 0.112 & 0.436 \\
\hline
\end{tabular}

* $p$-value $<0.05$ is considered as significant.
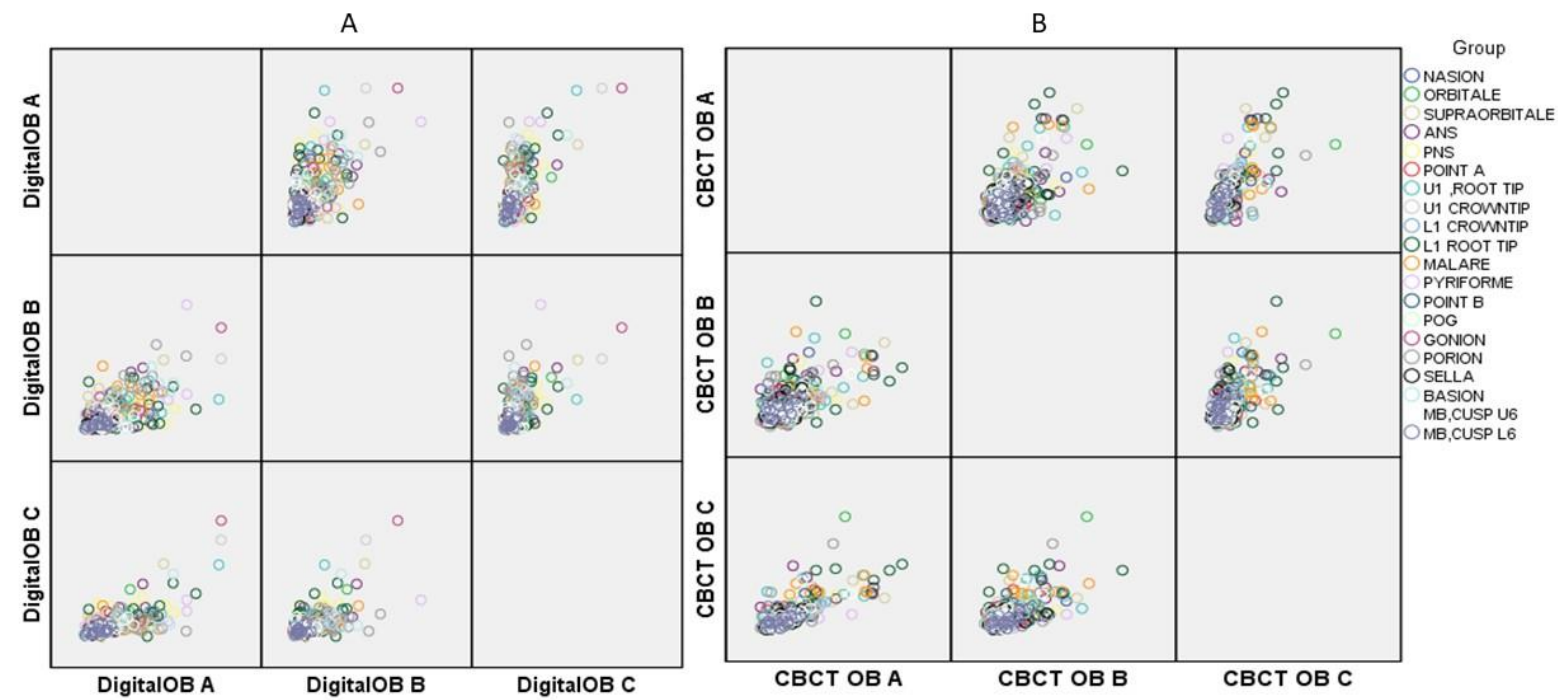

Figure 1. Graph showing associations in the observations taken by three observers in (A) Digital (B) cone beam computed tomography (CBCT). 


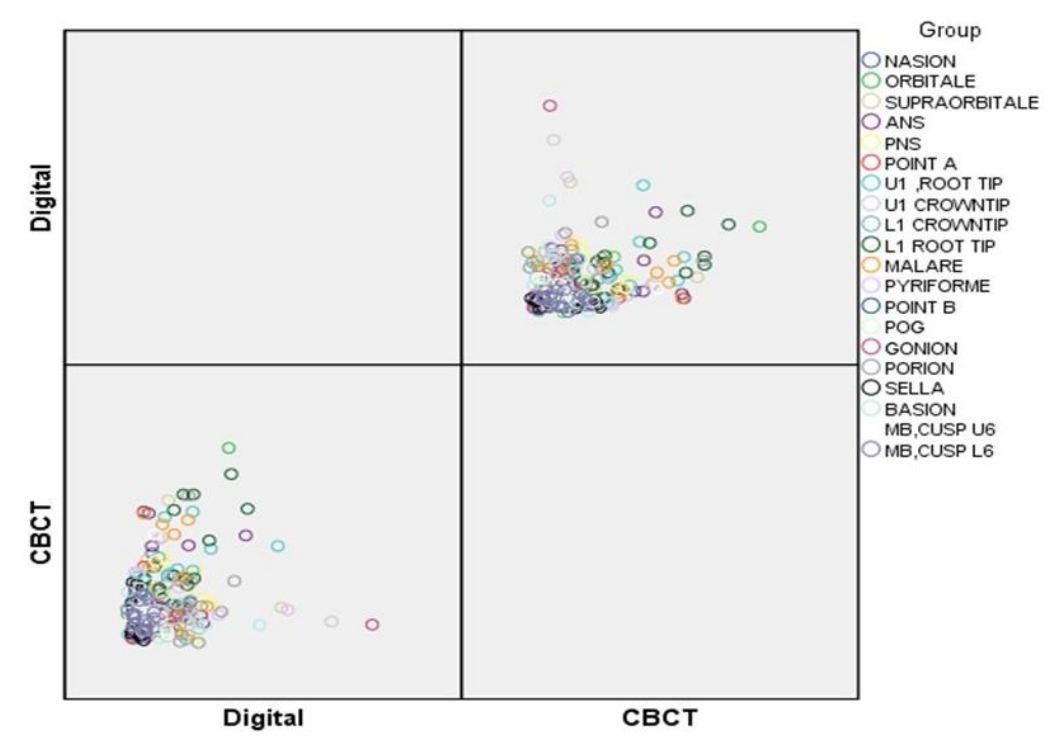

Figure 2. Inter-observer comparison of the plotting of the landmarks between the Digital and CBCT images.

\section{Discussion}

Cleft lip and/or palate $(\mathrm{CL} \pm \mathrm{P})$ malformations are the most common congenital abnormalities in the craniofacial region and present a severe problem for health delivery systems throughout the world. Depending on the ethnicity and geographic location of the population, wide variations in the prevalence of cleft lip and palate have been reported, with higher rates amongst Asians and American Indians (one in 500 births). An isolated cleft palate is more frequently found in females than in males, at a ratio of 2:1. In contrast, there is a 2:1 male-to-female ratio for cleft lip with or without cleft palate [36].

Owing to their knowledge of the craniofacial complex and their expertise in tooth movement and dentofacial management, orthodontists' role in the cleft palate team is indispensable. Orthodontic treatment can have a dental effect, orthopedic reverberations, or both [37], but a prerequisite for successful orthodontic management is an understanding of the site, extent, and severity of the cleft-related craniofacial dysmorphology. The advancements in technology and the incorporation of novel methods aid in striving toward an accurate diagnosis. Researchers have worked diligently to achieve a micro-level accuracy in landmark identification, even comparing the efficiency in the projection of different CBCT machines [31] with a deluge of articles on the same. However, there is a paucity of data on landmark repeatability and reproducibility in the craniofacial morphologies of $\mathrm{CL} \pm \mathrm{P}$ patients, which is challenging to accomplish. Hence, the present study was undertaken in $\mathrm{CL} \pm \mathrm{P}$ patients to decipher the landmarks and verify their reproducibility so these can be applied clinically and aid in treatment planning.

The earlier studies regarding $\mathrm{CL} \pm \mathrm{P}$ and their analysis made use of cephalograms alone, as that was the only imaging modality available at the time. Hotz and Gnoinski [7] advised that caution should be used in the interpretation of results involving point PNS and point A, whereas Mølsted et al. [8] reported errors for the skeletal variables like point A, ANS, and PNS. The ANS and PNS points were both statistically significant in the present study.

The Nasion and Orbitale points were not significant in our study, which is in accordance with Grauer D et al. [28] who observed similar results, whereas Chang ZC et al. [29] implied that the identification error increased at the Nasion and Orbitale on the CBCTderived cephalograms. Ludlow JB et al. [21] concluded that the Nasion and Orbitale had no significant variation in anterior-posterior (AP) measurement but had a significant variation of caudal cranial (CC) values. Moreover, Chien PC et al. [3] also presented no variation in the Nasion in inter and intra-observer variation, whereas significant inter-observer 
variation was perceived in the Orbitale. Lagravère MO et al. [38] concluded that the mean difference for the Nasion was not high, but the Orbitale showed a high mean difference. The landmarks of Gonion, Nasion, Orbitale, and Anterior Nasal Spine (ANS) showed the most considerable median Euclidean distances for both intra- and inter-observer measurements according to Katkar et al. 2013 [31]. According to Durao APR et al., the Gnathion $(\mathrm{Gn})$ point was the least reliable landmark for orthodontists, while the Orbitale (Or) was the least reliable landmark for dentomaxillofacial radiologists [32].

The supraorbitale point presented with statistically non-significant values, however. Turhan-Haktanir $\mathrm{N}$ et al. [39] studied records of 399 patients on computed tomography (CT) and concluded that the presence of a double foramen/notch was higher on the right side as cephalograms are usually taken from the right. Moreover, various types of supraorbital transcranial exits were observed by Kyu LN 2019 [40], of which the frontal notch was the most common. Woo SW et al. [41] also revealed the variation and characteristics of the supraorbital foramen or notch in a Korean population based on 3D-CT images. These findings were in contrast to those of the present study.

The anterior nasal spine $(p \leq 0.05)$ point was significantly variable in inter-observer tracings. Similar findings were made by Ludlow JB et al. [21], Grauer D et al. [28], McClure SR 2005 [27], and Durao APR [32], wherein the ANS showed significant variation along with point A [6,21,27], Condylion [28,32], and Gnathion [21,33]. Conventional landmarks such as points $\mathrm{A}, \mathrm{ANS}$, and PNS are challenging to mark in children with unilateral cleft lip and palate (UCLP). However, in a study by Bongaarts CA [6], no other landmarks were found to be easier to trace. Care should be taken while interpreting the results of cephalometric studies in UCLP patients, due to inter-observer tracings, digitization, and, therefore, measurement errors utilizing landmarks like points A, ANS, and PNS [6]. Chang ZC et al. [29] also showed a positive correlation, implying that the identification error increased at the ANS on the CBCT-derived cephalograms. An intraclass correlation coefficient (ICC) of more than $15 \%$ was found by Chien PC et al. [3], who showed significant variation in the inter-examiner evaluation.

Due to a significant shift from the midline in the premaxillary region of young patients, a variation in the ANS can be explained [42]. Point PNS can be influenced by a possible palatal shelf rotation from the centerline and/or a deficiency in the size of the posterior palate [42].

The posterior nasal spine $(p \leq 0.05)$ presented with significant inter-observer tracings. Chang ZC et al. [29] showed an increased error in the landmark identification of the PNS. Bonagaarts CA [6] along with Ludlow JB et al. [21] and Ghoneima A [34] also presented significant variations. However, no variation in the PNS was found in a study by Chien PC et al. [3]. Lagravère MO et al. [38] also inferred the difference in the plotting of point PNS in the X-axis for both the inter- and intra-examiner evaluation.

The root tip of the maxillary and the mandibular incisor showed significant variability. These findings are in agreement with that of Chien PC et al. [3], who had a significant variation for the lower incisor root tip, but no significant finding for the upper incisor roots. Similar observations were reported by Chang ZC et al. [29], with significant findings in the root apex of the maxillary and the mandibular incisor root apex. The reason for the difficulty of root tip identification can be attributed to tooth germ moulding, unerupted teeth in the anterior part of the maxilla, and a reduced radio-opacity due to the presence of cleft [7]. Our study shows no significant finding for incisor tips. However, Grauer D et al. [28] also showed a significant variation in the maxillary incisor tip. Additionally, Ludlow JB et al. [21] and Ghoneima A [34] presented significant findings on the maxillary and mandibular incisor tips.

In the present study, the points malare and pyriforme had a significant discrepancy. These findings are in conjugation with Suri S et al. [37], who measured the asymmetry of these two points using axial and transverse $\mathrm{CT}$ slices and noted no significant measurement for the malare, but a significant reduction in the sagittal positioning of the pyriforme on the cleft side. 
Significant variability was observed in bilateral landmarks like the porion, along with the basion. Chang ZC et al. [29] and Ghoneima A [34] showed that there was a positive regression correlation for the basion with a high variability, but no significance for the gonion, which was found to be significant in studies conducted by Ludlow JB et al. [21], Katkar RA et al. [31], and Park J et al. [20]. The variation in the porion can be attributed to the difference in opinion in localizing the point. Some authors consider the porion as a landmark in the soft tissues of the ear canal, whereas others feel it is on a bone/soft-tissue margin. A high variability was observed by Chang ZC et al. [29] and Durao APR [32]. Chien PC et al. [3] revealed a very high degree of variability for the basion for both the intra- and inter-observer evaluation, whereas the porion and gonion showed a significant variation in the Y-axis for inter-observer variability.

Since no study was available for comparing the landmark identification errors in patients with $\mathrm{CL} \pm \mathrm{P}$, the comparison was made with present studies published on the general population. Many articles have been published concerning the use of CBCT in patients with a cleft lip and/or palate ( $C L \pm P$ ). Now, $C B C T$ has been proven to be a better choice for assessing bone volume, deficiencies, and root development, because it provides a better image quality at a significantly lower radiation dose. However, no evidence is available, showing that $\mathrm{CBCT}$ is more informative than $2 \mathrm{D}$ concerning facial soft-tissue analysis in patients with CLP.

CBCT scans should be carried out while weighing the pros and cons. It can be regarded as a highly reliable diagnostic tool in both simple and complex cases with CLP where 3D assessment is mandatory for making the most appropriate therapeutic decision.

\section{Limitations}

The primary limitation can be attributed to the non-inclusion of bilateral cleft lip and palate patients, who also constitute a large proportion of patients with a cleft lip and palate. The identification of landmarks in cases of cleft lip and palate is arduous, and not all observers are able to localize the points in a similar manner. In the present study, accuracy may have been affected by the operator's skills, expertise, and exhaustion due to frequently repeated measurements. In addition, the present study was a retrospective analysis; therefore, clinical examination of the study sample could not be done and relied solely on the medical records and data.

\section{Conclusions}

1. The CBCT images provide a significantly more precise location of the anterior nasal spine, Point A, posterior nasal spine, pyriforme, and malare, overcoming the problem caused due to clefting in the nasomaxillary complex.

2. Bilateral landmarks like the porion, gonion, and basion were also significantly more precise in CBCT images when compared with digital cephalograms.

Author Contributions: Conceptualization, A.S.K., M.S.S., M.P., L.P. and G.K.K.; methodology, A.S.K., M.S.S., M.P., L.N., V.G. and F.d.; software, A.S.K., M.P., L.N., F.d. and L.P.; analysis, R.B.; investigation, G.K.K., F.d. and L.P.; resources, G.K.K., F.d. and L.P.; data curation, G.K.K.; writing-original draft preparation, A.S.K., M.S.S., G.K.K., R.B., L.N., F.d., L.P., V.G. and H.D.; writing-review and editing, H.D. and G.K.K.; visualization, H.D. and G.K.K.; supervision, H.D., G.K.K., F.d., V.G. and L.P.; project administration, A.S.K. All authors have read and agreed to the published version of the manuscript.

Funding: This research received no external funding.

Institutional Review Board Statement: The study was conducted according to the guidelines of the Declaration of Helsinki, and approved by the Institutional Review of SGT Dental College, Hospital, and Research Institute, Budhera, Gurgaon, India (SGTDC/PPL/Com./E.C./14Aug2010) (institutional ethical committee). Willingness to participate in the study was obtained. All records acquired from Department Orthodontics and Dentofacial Orthopedics from March 2011 to May 2013 were used only for research purposes.

Informed Consent Statement: Informed consent was obtained from all subjects involved in the study. 
Data Availability Statement: The data presented in this study are available on request from the corresponding author.

Acknowledgments: The authors acknowledge Sunjay Suri, BDS, MDS, MOrth RCS (Edinburgh), DNB, DIBO, FRCDC, FACD, FICD, Professor and Director, Graduate Orthodontics, Faculty of Dentistry, University of Toronto for constant guidance and motivation.

Conflicts of Interest: The authors declare no conflict of interest.

\section{References}

1. Houston, W. The analysis of errors in orthodontic measurements. Am. J. Orthod. 1983, 83, 382-390. [CrossRef]

2. Gupta, A.; Kharbanda, O.P.; Balachandran, R.; Sardana, V.; Kalra, S.; Chaurasia, S.; Sardana, H.K. Precision of manual landmark identification between as-received and oriented volume-rendered cone-beam computed tomography images. Am. J. Orthod. Dentofac. Orthop. 2017, 151, 118-131. [CrossRef]

3. Chien, P.C.; Parks, E.; Eraso, F.; Hartsfield, J.; Roberts, W.; Ofner, S. Comparison of reliability in anatomical landmark identification using two-dimensional digital cephalometrics and three-dimensional cone beam computed tomography in vivo. Dentomaxillofacial Radiol. 2009, 38, 262-273. [CrossRef]

4. Kragskov, J.; Bosch, C.; Gyldensted, C.; Sindet-Pedersen, S. Comparison of the reliability of craniofacial anatomic landmarks based on cephalometric radiographs and three-dimensional CT scans. Cleft Palate Craniofacial J. 1997, 34, 111-116. [CrossRef] [PubMed]

5. Tulunoglu, O.; Esenlik, E.; Gulsen, A.; Tulunoglu, I. A comparison of three-dimensional and two-dimensional cephalometric evaluations of children with cleft lip and palate. Eur. J. Dent. 2011, 5, 451-458. [CrossRef] [PubMed]

6. Bongaarts, C.A.; van't Hof, M.A.; Prahl-Andersen, B.; Kuijpers-Jagtman, A.M. Identification of cephalometric landmarks in unilateral cleft lip and palate patients: Are there alternatives for Point A, ANS, and PNS? Cleft Palate Craniofacial J. 2008, 45, 81-86. [CrossRef] [PubMed]

7. Hotz, M.; Gnoinski, W. Comprehensive care of cleft lip and palate children at Zürich University: A preliminary report. Am. J. Orthod. 1976, 70, 481-504. [CrossRef]

8. Mølsted, K.; Asher-MacDade, C.; Brattström, V.; Dahl, E.; Mars, M.; McWilliam, J.; Plint, D.A.; Prahl-Andersen, B.; Semb, G.; Shaw, W.C.; et al. A six-center international study of treatment outcome in patients with clefts of lip and palate: Part Craniofacial form and soft tissue profile. Cleft Palate Craniofacial J. 1992, 29, 398-404. [CrossRef]

9. Brattström, V.; Mølsted, K.; Prahl-Andersen, B.; Semb, G.; Shaw, W.C. The Eurocleft study: Intercenter study of treatment outcome in patients with complete cleft lip and palate. Part 2: Craniofacial form and nasolabial appearance. Cleft Palate Craniofacial J. 2005, 42, 69-77. [CrossRef]

10. Kawamata, A.; Ariji, Y.; Langlais, R.P. Three-dimensional computed tomography imaging in dentistry. Dent. Clin. N. Am. 2000, 44, 395-410.

11. Garib, D.G.; Yatabe, M.S.; Ozawa, T.O.; Filho, O.G. Alveolar bone morphology in patients with bilateral complete cleft lip and palate in the mixed dentition: Cone beam computed tomography evaluation. Cleft Palate Craniofacial J. 2012, 49, 214-229. [CrossRef] [PubMed]

12. Buyuk, S.K.; Ercan, E.; Celikoglu, M.; Sekerci, A.E.; Hatipoglu, M. Evaluation of dehiscence and fenestration in adolescent patients affected by unilateral cleft lip and palate: A retrospective cone beam computed tomography study. Angle Orthod. 2016, 86, 431-436. [CrossRef] [PubMed]

13. Ercan, E.; Celikoglu, M.; Buyuk, S.K.; Sekerci, A.E. Assessment of the alveolar bone support of patients with unilateral cleft lip and palate: A cone-beam computed tomography study. Angle Orthod. 2015, 85, 1003-1008. [CrossRef] [PubMed]

14. Linderup, B.W.; Küseler, A.; Jensen, J.; Cattaneo, P.M. A novel semiautomatic technique for volumetric assessment of the alveolar bone defect using cone beam computed tomography. Cleft Palate Craniofacial J. 2015, 52, 47-55. [CrossRef]

15. Celebi, A.A.; Ucar, F.I.; Sekerci, A.E.; Caglaroglu, M.; Tan, E. Effects of cleft lip and palate on the development of permanent upper central incisors: A cone-beam computed tomography study. Eur. J. Orthod. 2014, 37, 544-549. [CrossRef]

16. Starbuck, J.M.; Ghoneima, A.; Kula, K. Facial soft-tissue asymmetry in three-dimensional cone-beam computed tomography images of children with surgically corrected unilateral clefts. J. Craniofacial Surg. 2014, 25, 476-480. [CrossRef]

17. Zhang, X.; Zhang, Y.; Yang, L.; Shen, G.; Chen, Z. Asymmetric dental development investigated by cone-beam computed tomography in patients with unilateral cleft lip and alveolus. Cleft Palate Craniofacial J. 2016, 53, 413-420. [CrossRef]

18. Zhou, W.; Li, W.; Lin, J.; Liu, D.; Xie, X.; Zhang, Z. Tooth lengths of the permanent upper incisors in patients with cleft lip and palate determined with cone beam computed tomography. Cleft Palate Craniofacial J. 2013, 50, 88-95. [CrossRef]

19. Papi, P.; Giardino, R.; Sassano, P.; Amodeo, G.; Pompa, G.; Cascone, P. Oral health related quality of life in cleft lip and palate patients rehabilitated with conventional prostheses or dental implants. J. Int. Soc. Prev. Community Dent. 2015, 5, $482-487$. [CrossRef]

20. Park, J.; Baumrind, S.; Curry, S.; Carlson, S.K.; Boyd, R.L.; Oh, H. Reliability of 3D dental and skeletal landmarks on CBCT images. Angle Orthod. 2019, 89, 758-767. [CrossRef]

21. Ludlow, J.B.; Gubler, M.; Cevidanes, L.; Mol, A. Precision of cephalometric landmark identification: Cone-beam computed tomography vs conventional cephalometric views. Am. J. Orthod. Dentofac. Orthop. 2009, 136, 312.e1-312.e10. [CrossRef] 
22. Kochhar, A.S.; Sidhu, M.S.; Prabhakar, M.; Bhasin, R.; Kochhar, G.K.; Dadlani, H.; Spagnuolo, G.; Mehta, V.V. Intra- and Interobserver Reliability of Bone Volume Estimation Using OsiriX Software in Patients with Cleft Lip and Palate Using Cone Beam Computed Tomography. Dent. J. 2021, 9, 14. [CrossRef] [PubMed]

23. de Oliveira, A.E.F.; Cevidanes, L.H.S.; Phillips, C.; Motta, A.; Burke, B.; Tyndall, D. Observer reliability of three-dimensional cephalo-metric landmark identification on cone-beam computerized tomography. Oral Surg. Oral Med. Oral Pathol. Oral Radiol. Endodontol. 2009, 107, 256-265. [CrossRef] [PubMed]

24. Naji, P.; Alsufyani, N.; Lagravere, M. Reliability of anatomic structures as landmarks in three-dimensional cephalometric analysis using CBCT. Angle Orthod. 2014, 84, 762-772. [CrossRef]

25. Kochhar, A.S.; Sidhu, M.S.; Prabhakar, M.; Bhasin, R.; Kochhar, G.K.; Dadlani, H.; Spagnuolo, G. Frontal and axial evaluation of craniofacial morphology in repaired unilateral cleft lip and palate patients utilizing cone beam computed tomography; an observational study. Int. J. Environ. Res. Public Health 2020, 17, 7786. [CrossRef]

26. De Grauwe, A.; Ayaz, I.; Shujaat, S.; Dimitrov, S.; Gbadegbegnon, L.; VandeVannet, B.; Jacobs, R. CBCT in orthodontics: A systematic review on justification of CBCT in a paediatric population prior to orthodontic treatment. Eur. J. Orthod. 2019, 41, 381-389. [CrossRef]

27. McClure, S.R.; Sadowsky, P.L.; Ferreira, A.; Jacobson, A. Reliability of digital versus conventional cephalometric radiology: A comparative evaluation of landmark identification error. Semin. Orthod. 2005, 11, 98-110. [CrossRef]

28. Grauer, D.; Cevidanes, L.S.H.; Styner, M.; Heulfe, I.; Harmon, E.T.; Zhu, H.; Proffit, W.R. Accuracy and landmark error calculation using cone-beam computed tomography-generated cephalograms. Angle Orthod. 2010, 80, 286-294. [CrossRef]

29. Chang, Z.C.; Hu, F.C.; Lai, E.; Yao, C.C.; Chen, M.H.; Chen, Y.J. Landmark identification errors on cone-beam computed tomography-derived cephalograms and conventional digital cephalograms. Am. J. Orthod. Dentofac. Orthop. 2011, 140, e289-e297. [CrossRef]

30. Zamora, N.; Llamas, J.; Cibrian, R.; Gandia, J.; Paredes, V. A study on the reproducibility of cephalometric landmarks when undertaking a three-dimensional (3D) cephalometric analysis. Med. Oral Patol. Oral Cir. Bucal. 2012, 17, e678-e688. [CrossRef]

31. Katkar, R.A.; Kummet, C.; Dawson, D.; Uribe, L.M.; Allareddy, V.; Finkelstein, M.; Ruprecht, A. Comparison of observer reliability of three-dimensional cephalometric landmark identification on subject images from Galileos and i-CAT cone beam CT. Dentomaxillofacial Radiol. 2013, 42, 20130059. [CrossRef] [PubMed]

32. Durão, A.P.R.; Morosolli, A.; Pittayapat, P.; Bolstad, N.; Ferreira, A.P.; Jacobs, R. Cephalometric landmark variability among orthodontists and dentomaxillofacial radiologists: A comparative study. Imaging Sci. Dent. 2015, 45, 213.

33. da Neiva, M.B.; Soares, Á.C.; Lisboa, C.d.O.; Vilella, O.d.V.; Motta, A.T. Evaluation of cephalometric landmark identification on CBCT multiplanar and 3D reconstructions. Angle Orthod. 2015, 85, 11-17. [CrossRef] [PubMed]

34. Ghoneima, A.; Cho, H.; Farouk, K.; Kula, K. Accuracy and reliability of landmark-based, surface-based and voxel-based 3D cone-beam computed tomography superimposition methods. Orthod. Craniofacial Res. 2017, 20, 227-236. [CrossRef] [PubMed]

35. Chen, Y.-J.; Chen, S.-K.; Yao, C.-C.J.; Chang, H.-F. The effects of differences in landmark identification on the cephalometric measurements in traditional versus digitized cephalometry. Angle Orthod. 2004, 74, 155-161.

36. Mossey, P.A.; Little, J.; Munger, R.G.; Dixon, M.J.; Shaw, W.C. Cleft lip and palate. Lancet 2009, 374, 1773-1785. [CrossRef]

37. Suri, S.; Utreja, A.; Khandelwal, N.; Mago, S.K. Craniofacial computerized tomography analysis of the midface of patients with repaired complete unilateral cleft lip and palate. Am. J. Orthod. Dentofac. Orthop. 2008, 134, 418-429. [CrossRef]

38. Lagravère, M.O.; Low, C.; Flores-Mir, C.; Chung, R.; Carey, J.P.; Heo, G.; Major, P.W. Intraexaminer and interexaminer reliabilities of landmark identification on digitized lateral cephalograms and formatted 3-dimensional cone-beam computerized tomography images. Am. J. Orthod. Dentofac. Orthop. 2010, 137, 598-604. [CrossRef]

39. Turhan-Haktanır, N.; Ayçiçek, A.; Haktanır, A.; Demir, Y. Variations of supraorbital foramina in living subjects evaluated with multidetector computed tomography. Head Neck 2008, 30, 1211-1215. [CrossRef]

40. Lim, N.K.; Kim, Y.H.; Kang, D.H. Precision analysis of supraorbital transcranial exits using three dimensional multidetector computed tomography. J. Craniofacial Surg. 2019, 30, 1894-1897. [CrossRef]

41. Woo, S.W.; Lee, H.J.; Nahm, F.S.; Lee, P.B.; Choi, E. Anatomic characteristics of supraorbital foramina in Korean using threedimensional model. Korean J. Pain 2013, 26, 130-134. [CrossRef] [PubMed]

42. Atherton, J.D. A descriptive anatomy of the face in human fetuses with unilateral cleft lip and palate. Cleft Palate Craniofacial J. $1967,4,104-114$. 